\title{
Painful and Indurated Hyperchromic Cord of the Arm: Throm- bophlebitis of the Cephalic Vein
}

\author{
Ibrahima Niang 1,*, Pape Matar Kandji 2, Waly Niang Mboup ${ }^{3}$, Hamza Souhail 1, Mamadou Ly 1, Papa Abdou \\ Diop ${ }^{1}$, Abdoulaye Dione Diop ${ }^{1}$, Sokhna Ba ${ }^{1}$
}

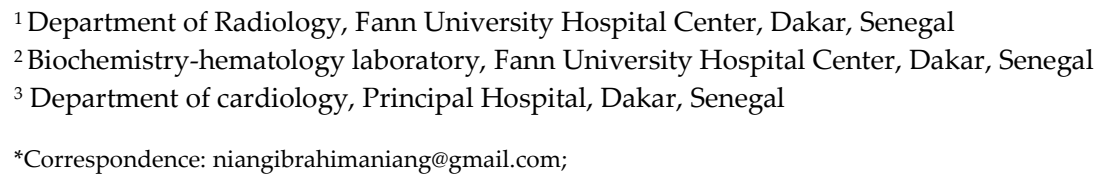

How to cite this paper: Niang, I., Kandji, P. M., Mboup, W. N., Souhail, H., Ly, M., Diop, P. A., Diop, A. D., \& Ba, S. (2021). Painful and Indurated Hyperchromic Cord of the Arm: Thrombophlebitis of the Cephalic Vein. Global Journal of Medical Case Reports, 1(1), 5-7. Retrieved from https://www.scipublications.com/journal/index.php/gimcr/article/view/63
Received: June 22, 2021 Accepted: July 26, 2021 Published: July 27, 2021

Copyright: (C) 2021 by the authors. Submitted for possible open access publication under the terms and conditions of the Creative Commons Attribution (CC BY) license (http://creativecommons.org/licenses /by/4.0/).

\begin{abstract}
We here report a case of an acute cephalic vein thrombophlebitis in a 34-year-old female patient with no known thromboembolic risk factors and no medical history or ongoing treatment. We present the images of her diagnosis, which was made in the presence of a painful and indurated hyperchromic cord of the arm and confirmed by Doppler ultrasound. In the absence of deep extension of the thrombus, his management was limited to a symptomatic treatment without anticoagulation and the symptomatology was amended without complication or recurrence.
\end{abstract}

Keywords: Superficial venous thrombosis, upper limbs thrombosis, cephalic vein thrombosis, doppler ultrasound

\section{Introduction}

A superficial venous thrombosis is a thrombosis involving a vein of the superficial venous network. The term superficial thrombophlebitis can be used in the case of an inflammatory reaction of the wall of the thrombosed vein [1]. It can be considered benign in the absence of extension into the deep network or associated pulmonary embolism. But there is a continuum with these thromboembolic diseases, so some authors deny this benignity $[2,3]$. We here report a case of an acute cephalic vein thrombophlebitis in a 34year-old female patient with no known thromboembolic risk factors and no medical history or ongoing treatment. In the absence of deep extension of the thrombus, his management was limited to a symptomatic treatment without anticoagulation and the symptomatology was amended without complication or recurrence.

\section{Case presentation}

This is a 34-year-old female patient, non-obese without past medical history and not under any treatment. She presented in consultation for pain in her right arm for the past 3 days. The pain occurred spontaneously, limited to the arm, without any notion of trauma and the patient did not complain of anything else. Clinical examination revealed an indurated, hyperchromic and painful subcutaneous cord in the lower $2 / 3$ of the anterior aspect of the right arm (figure $1 \mathrm{~A}$ ).

Doppler ultrasonography of the right upper limb revealed a hypoechoic thrombus in the right cephalic vein which is dilated, incompressible and without Doppler flow (Figure 1 B C). This thrombus is extended over the distal $2 / 3$ of the cephalic vein.

The other superficial and deep veins of the limb were permeable, as were the arteries. The diagnosis of superficial venous thrombosis of the right upper limb involving the cephalic vein was retained. In addition, a check-up was carried out to determine the etiology of this superficial venous thrombosis. This etiological research was limited to the clinical 
examination for thrombogenic factors and to a standard biological workup. Exhaustive biological analyses could not be performed due to lack of resources. However, in the context of the COVID-19 pandemic, an antibody test was performed but was negative for both IgM and IgG. Therefore, the factor at the origin of this cephalic venous thrombosis remained unidentified.

In the absence of deep thrombosis extension, treatment was limited to analgesics and anti-inflammatories, without anticoagulation. The pain subsided three days later with persistence of the induration but there were no further events. An ultrasound examination performed one week later did not reveal any extension of the thrombus. After 3 months of follow-up, there were no complications or other thrombotic events.

\section{Discussion}

A superficial venous thrombosis is a thrombosis involving a vein of the superficial venous network. The term superficial thrombophlebitis can be used in the case of an inflammatory reaction of the wall of the thrombosed vein [1].

This is a relatively frequent condition, but quite rare in the upper limbs outside the presence of a central venous catheter [4,5]. Its diagnosis is based on the clinical triad: pain, redness, induration. It is confirmed by ultrasound doppler, which must also look for possible extension of the thrombus to the deep venous network. This extension conditions both the therapeutic attitude and the prognosis.

Elements of this clinical triad are not always easily identifiable in melanoderma and can also be found in lymphangitis or hypodermitis, which are the main differential diagnoses. This imposes the systematic use of ultrasound doppler to confirm the diagnosis of superficial venous thrombosis [6].

After the positive diagnosis, which is rather easy, the main challenge is to find the etiological factor(s) of superficial venous thrombosis. The most common factors are the presence of endovenous material, which is the case in 85\% [7]. Other factors are constitutional thrombophilia, the presence of protein $S$ and antithrombin, protein $C$ deficiency, autoimmune and inflammatory diseases and paraneoplastic syndromes.

Superficial venous thrombosis can be considered benign when isolated, but it is important to know that there is a continuum between superficial venous thrombosis, deep venous thrombosis and pulmonary embolism, since they share the same thromboembolic factors. Therefore, its benign character is discussed by several authors $[2,3]$.

In conclusion, we say that superficial venous thrombosis is rare in the upper limb, except in the presence of a central venous catheter. Its diagnosis can be easily evoked by the clinic, but it must be confirmed by Doppler ultrasonography, which allows to rule out its differential diagnoses and to specify the absence of extension in the deep network. The etiological research constitutes the main challenge in the management of superficial venous thrombosis of the limbs in a patient without known risk factors. In the absence of extension into the deep network or exceptionally of pulmonary embolism, anticoagulant treatment is not mandatory. 


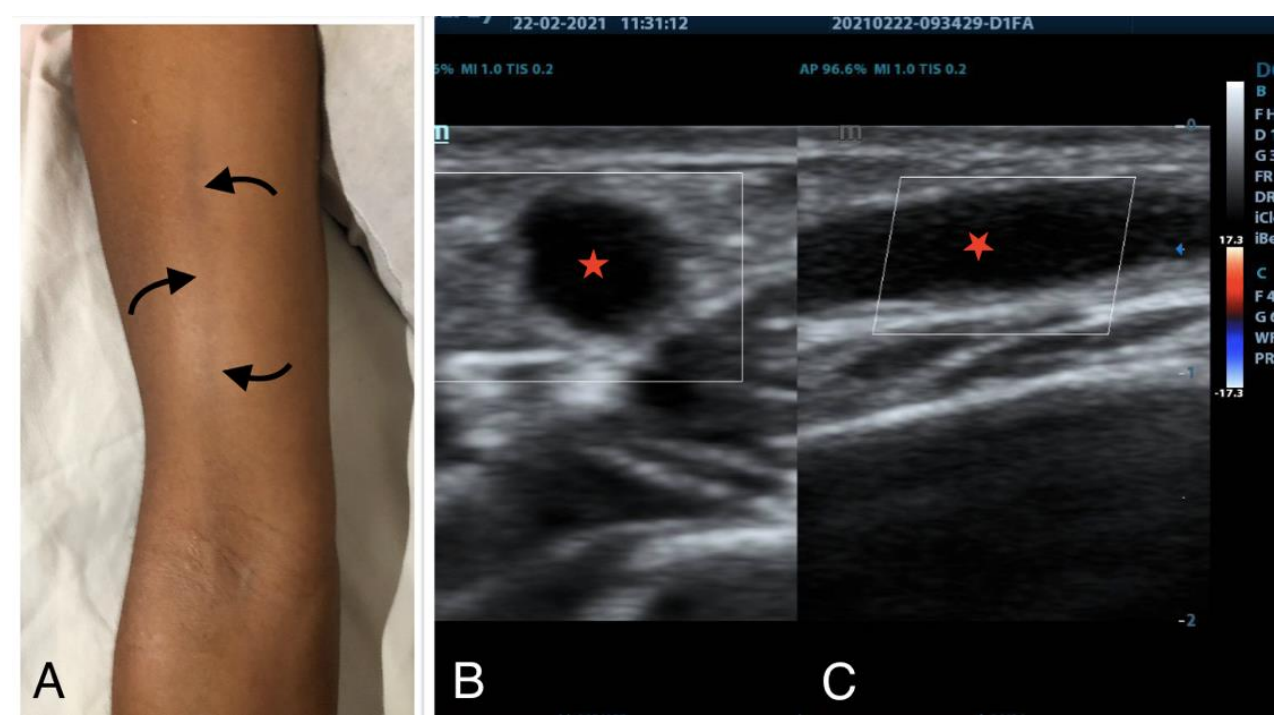

Figure 1. A) Photograph of the right arm showing the hyperchromic cord, indicated by the black curved arrows. B) Axial view of the incompressible cephalic vein dilated by hypoechoic thrombus (red star), without Doppler flow. C) Longitudinal view of the cephalic thrombosis, extended with a hypoechogenic thrombus (red star)

\section{References}

[1] Minvielle F. Les thromboses veineuses superficielles. Archives des maladies du coeur et des vaisseaux Pratique. 2014;(231):21-30.

[2] Meddeb Z, Bellakhal S, Souissi A, Kaab BB, Mestiri A, Douggui MH. Les thromboses veineuses superficielles: un regain d'intérêt légitime. La Revue de Médecine Interne. 2015;36:A84-5.

[3] Becker F, Quéré I, Guenneguez H, Mismetti P, Leizorovicz A, Decousus H. La thrombose veineuse superficielle: une pathologie à reconsidérer. Sang Thrombose Vaisseaux. 2011;23(6):280-91.

[4] Abou Kassem CP. Thromboses veineuses du membre supérieur: prise en charge hospitalière et devenir. 2018;

[5] Kwiecien GJ, Coombs DM, Sinclair N, Gastman BR, Bassiri Gharb B, Rampazzo A. Acute Superficial Vein Thrombosis of the Upper Extremity: A Case Report. Plast Reconstr Surg Glob Open. déc 2020;8(12):e3322.

[6] Rachdi E, Bellakhal S, Guediche NH, Kaab BB, Souissi A, Douggui MH. Thromboses veineuses superficielles: un problème plus profond que leur nom l'indique! La Revue de Médecine Interne. 2017;38:A111.

[7] Ploton G, Pistorius M-A, Raimbeau A, Denis Le Seve J, Bergère G, Ngohou C, et al. A STROBE cohort study of 755 deep and superficial upper-extremity vein thrombosis. Medicine (Baltimore). févr 2020;99(6): e18996. 